\title{
Electronic games abuse and mental disorder common in young students in southern Brazil
}

\begin{abstract}
Introduction: The use of electronic games has become frequent among youngs, however, the abusive use of games and the implications of such behavior are still poorly understood.
\end{abstract}

Objectives: To evaluate the prevalence of abusive use of electronic games and associated factors in high school students in the urban area of Pelotas-RS.

Methods: A cross-sectional study carried out in the urban perimeters of the city of Pelotas, Rio Grande do Sul, Brazil. Socio-demographic variables, school performance, common mental disorders by the Self-Reporting Questionnaire (SRQ-20) and game addiction by Game Addiction Scale (GAS) were evaluated.

Results: The prevalence of abuse of games was $8.6 \%$. Being a male (RP $3.79 \mathrm{CI}$ 95\% 1.42-10.1), being a repetitive scholar (RP2,15IC95\% 2,99-8,39) and manifesting common mental disorders (RP $5.7395 \%$ CI 2.29- 14,3) are factors associated with abusive use of electronic games.

Discussion: The high prevalence of abusive use of games in association with lower school performance and the presence of common mental disorders should be studied more broadly, since such phenomenon may be one of the determinants for not achieving the complete physical, mental and social well-being of these young people.
Volume 9 Issue 5 - 2018

Samuelle Gonçalves e Gonçalves,' Luísa Mendonça de Souza Pinheiro, ${ }^{2}$ Ricardo Tavares Pinheiro,' Karen Amaral Tavares Pinheiro'

'Graduate Program in Health and Behavior, Catholic University of Pelotas, Brazil

${ }^{2}$ School of Medicine, Catholic University of Pelotas, Brazil

Correspondence: Karen Amaral Tavares Pinheiro, Catholic University of Pelotas, Postgraduate Program in Health and Behavior, Gonçalves Chaves Street, 377, sala 4II C, CEP 960I5560, Pelotas, Rio Grande do Sul, Brazil, Tel 55532I288404, Email karinap@terra.com.br

Received: November 13, 2017 | Published: October 25, 2018

Keywords: electronic games, adolescents, mental disorders

Abbreviations: ADHD, Disorder Attention Deficit Hyperactivity Disorder; CMD, common mental disorders; DSM 5, diagnostic and statistical manual os mental disorders; GAS, game addiction scale; SRQ-20, self-reporting questionnaire

\section{Introduction}

In the last decades there has been a great technological advance, especially in the sectors related to electronics and computer science, which has provided a wide use of the Internet and electronic games. The game industry, in particular, experienced significant growth, the popularization and globalization of electronic games. Different populations with different sócio-cultural levels and of the most diverse ages are being impacted by this phenomenon. This new reality has generated many doubts about the influence of such games on the behavior and health of the player, especially in young people. ${ }^{1,2}$ One of the most worrisome factors is the possibility of a specific diagnosis that determines a mental disorder due to the use of electronic games1. This field is still being investigated, but evidence of this possibility is already described in the Diagnosticand Statistical Manual Mental Disorders (DSM V), ${ }^{3}$ which in its annexes provides information about Internet Game Disorder such as the constant use of the internet in games, causing injury or suffering, such as persistently thinking about games, withdrawal symptoms, addiction and tolerance. Compulsive gambling behavior, paralysis of doing other activities that were considered pleasurable, social withdrawal, lying about the time spent playing, use of play to alleviate negative feelings, as well as serious damage in the spheres of education and/or work because of this behavior are signs and symptoms described in the DSM V. ${ }^{3}$ Studies report a prevalence of electronic game dependence around the world of approximately $3 \% 4$, predominantly male, in addition to association with depression, suicide, social anxiety disorder, generalized anxiety disorder, obsessive-compulsive disorder and disorder attention deficit hyperactivity disorder (ADHD), common mental disorders (CMD), chemical dependence, compulsive gambling, and eating disorders. ${ }^{4-6}$

Aspect also researched, in several countries of the world, is the association between abusive use of games and lower school performance. The results, however, are discordant: from the strong indication that abusive use may decrease scholastic/academic achievement, ${ }^{7-10}$ a non-association of these or even a benefit with increased use of games. studies that deal more complexly with the problem, there are those that link the number of hours as the determining factor for the lowest school performance. ${ }^{10}$ Some authors have argued that gambling may not harm or even be beneficial, ${ }^{11}$ there is a reference that increased use of computer games is strongly associated with increased reading and problem solving, particularly for girls and boys minors. ${ }^{12}$ The direction of the association between these factors seems not to be established and the disagreements are due to the different methodologies to approach the problem. The objective is to identify the prevalence of abusive use of electronic games and associated factors in high school students in the urban area of the city of Pelotas, RS, focusing on the association between abusive use of games, manifestation of CMD and school performance in students of the high school.

\section{Methods}

A cross-sectional study with high school students from the public and private schools of the city of Pelotas, aged between 13 and 24 years, who were able to read, understand and respond individually to the questionnaire, duly enrolled in the schools selected for the study, of Informed Consent signed. The sample calculation, using a prevalence of $4.5 \%$ of problematic use of electronic games, with an exposed and unexposed ratio of $1: 1$, risk 2 , power of $80 \%$ and reliability of $95 \%$, were estimated 451 respondents. The research was carried out with 
students from the public and private schools of the city of Pelotas, drawn through a list indicated by the State Department of Education. The school draw was governed by the percentage of students in both public and private networks, which resulted in a total of fifteen school institutions, twelve of which are public and three are private; it was estimated that 30 students from each school will be enrolled in classes established by the directorates. Three actions were established: the first with the direction to verify acceptance, establishment of the classes, dates and times of the meetings with the students; the second, in which the researcher passed the designated rooms to talk to the students, about the research and the informed consent, in that action was delivered the questionnaire that should be answered and returned anonymously at a later date, together with the informed consent; the third action was the collection of the completed questionnaires and the ICFs, and the questionnaires in which the ICF was duly signed were considered valid. The questionnaire consisted of questions of socioeconomic status evaluation and the ABEP questionnaire was used, specific questions related to its school performance, such as repetitions and low grades. In addition, two instruments were included in the Game Addiction Scale (GAS) ${ }^{13,14}$ Portuguese version, to measure the problematic use of electronic games and the SelfReporting Questionnaire (SRQ-20) ${ }^{15}$ to find prevalence of common mental disorders. SRQ-20 $0^{13}$ is a short version of SRQ-30 whose goal is the screening of non-psychotic mental disorders. The answers are dichotomous (yes/no). The higher the score, the greater the chance that the individual will present non-psychotic mental disorder (anxiety, depression and eating disorders). The cutoff points for the male and female individuals used were, respectively, 7 and 8 . The GAS instrument ${ }^{13,14}$ is a scale of 21 items, which can be divided into $07 \mathrm{sub}$ scales (components), each of which consists of 03 items. Sub scales are termed as: saliency, tolerance, mood modification, regression, relapse, conflict, and problems. The possible answers for each item are:

\section{Never. \\ 2. Rarely. \\ 3. Sometimes. \\ 4. Frequently. \\ 5. Very often.}

GAS indicates abusive use of games when an individual chooses at least two responses from: often or very often in at least four of the seven components. On the analysis, double data entry was performed in the Epinfo program, in addition to testing for inconsistencies in typing in the same software comparing the two data entries. After the final editing, the database was converted to the STATA program where a univariate analysis was performed to obtain a simple frequency of all variables, from the continuous measurements of central tendency and dispersion were made. The bivariate analysis to test the difference between proportions was done using the chi-square test, and the differences between two means were tested using Student's t-test and more than two means using the f-test (ANOVA). The Pearson coefficient was used to observe the behavior of two quantitative variables. Correlations were made by non-parametric test between the variables and the outcome. For all tests the level of significance was $5 \%(p<0.05)$. The independent effects of the variables on the outcome were estimated by the multivariate analysis. Poisson regression was used in the multivariate analysis and the variables that showed an association with the outcome with $p<0.2$ in the bivariate were considered eligible for adjustment. There was approval by the Research Ethics Committee of the Catholic University of Pelotas.

\section{Results and discussion}

The sample consisted of 450 young people. Most of them were female students $(54.9 \%)$. The mean age was 17.6 years $\mathrm{SD} \pm 2.4$. The lowest socioeconomic levels (D and E) were predominant with 56.8\%, followed by the C level (40.6\%) and the most favored levels (A and B) only $2.7 \%$. Among the private schools, $66 \%$ denied access to the research, which allowed $402(89.3 \%)$ students to be from the public network. As for academic achievement, $41.4 \%$ had never failed in high school. There was a high prevalence of CMD among students (36.9\%). Table 1 The prevalence of abuse of electronic games estimated by the GAS instrument was $8.6 \%$. Regarding the playing time, most players remain between 1 and 4 hours a day $(51.7 \%)$, but also noticed players who stay longer than this $(24.1 \%)$, however, were also noticed people who did not make no use of electronic games $(24.2 \%)$-Table 1 . In the bivariate analysis (tables 2 and 3 ) it is evidenced that there is no association between socioeconomic level and gambling abuse, as well as the trend of association between sex (95\% CI 0.99-5.37) and repetition (95\% CI 0.98-5.20), as well as the association with CMDs. After the adjustments between the variables, which in the bivariate analysis presented a $\mathrm{p}<0.2$, Poisson regression indicated that being male (RP3.79), had repeated high school (RP 2.99) and had CMD (RP 5.73) were associated with abusive use of games. Electronic games are one of the most widely used leisure tools in the world. But along with this behavior several doubts have been tied to the fact that video game games can be beneficial or harmful to adolescents and young adults. This is a central factor: that of being able to discern between the abusive use, the use and the non use of the electronic games. This discernment may give greater breadth of understanding of the phenomenon. Przybylski ${ }^{16-18}$ reports that there is a protective factor on all issues - physical and emotional, when the child uses little daily time, as well as a risk factor for excessive play. Our study indicates that the prevalence was $8.6 \%$, more than double that reported by Lemos $^{4}$ e Strittmatter. ${ }^{19}$ There is reason to question why we have such a high prevalence of abuse compared to other studies. The first of these is about the instrument that we use, since it is an instrument in the final validation phase, it could be overestimating our prevalence of abuse of the games, however, even if we consider that GAS is not the gold standard for this, when using other parameters that indicate dependence, such as the number of hours per session per day, we see a clear alignment with the instrument's result. Of the young people interviewed here, $24.1 \%$ used more than 4 hours a day or more than 30 hours a week, which indicates a high number of hours. Other study ${ }^{20}$ point out that as an indicator of abuse the use of more than 35 hours of games weekly, it is possible to think that of these $24.1 \%$ at least $1 / 3$ of them used 35 hours a week or more. This is a strong indication that the high prevalence should not be explained by the overestimation of GAS. Another indication that there is no overestimation is that when the socioeconomic level is observed, studies indicate that higher levels have a higher prevalence of abusive use of games. In our study, the highest levels did not represent $3 \%$, which would lead us to think the opposite, if our private schools had allowed their students to answer the questionnaires, our prevalence would be much higher. However, even when we group levels A, B and C we find the same prevalence as that found in the $\mathrm{D}$ and $\mathrm{E}$ levels grouped together. In the same direction we should think when we observe that our sample is constituted preferably by women, and we know that being male means a greater association in the direction of the increase of the appearance of the outcome in question. Thus, what is indicated is that we have a higher average prevalence of abusive use in this sample of young people when compared to other studies. 
Table I Description of the sample according to biopsychosocial variables and abuse of electronic games

\begin{tabular}{ll} 
Sex & \\
Male & $45,1 \%$ \\
Female & $54,9 \%$ \\
Socioeconomic Levels (ABEP) & \\
A-B & $2,7 \%$ \\
C & $40,6 \%$ \\
D-E & $56,8 \%$ \\
Common Mental Disorders (SRQ-20) & \\
Yes & $36,9 \%$ \\
No & $63,1 \%$ \\
Use of electronic games - Hours per day & \\
Does not use & $24,2 \%$ \\
Up to four hours & $51,7 \%$ \\
More than four hours & $24,1 \%$ \\
Repeated High School - Sometime in life & \\
Yes & $58,6 \%$ \\
No & $41,4 \%$ \\
Abusive Use of Games - Game Addiction Scale & \\
Yes & $8,6 \%$ \\
No & $91,4 \%$ \\
\hline
\end{tabular}

Table 2 Abusive use of games $X$ biopsychosocial variables

\begin{tabular}{lll}
\hline & Abusive use of games & p-value \\
\hline Sex & & 0,073 \\
Female & $5,2 \%$ & \\
Male & $11,2 \%$ & 0,282 \\
Socioeconomic Levels & & \\
A, B e C & $5,8 \%$ & \\
D e E & $9,3 \%$ & 0,110 \\
Repeated High School & & \\
Yes & $10,8 \%$ & \\
No & $5,3 \%$ & 0,010 \\
Common Mental Disorders & & \\
Yes & $15 \%$ & \\
No & $5,9 \%$ & \\
\hline
\end{tabular}

Table 3 Multivariate analysis by poisson regression - abusive use of games $X$ biopsychosocial variables

\begin{tabular}{lll}
\hline & Crude analysis & Adjusted analysis \\
\hline Sex: Male & $2,29(0,99-5,37)$ & $3,79(1,42-10,10)$ \\
Repeated High School & $2,15(0,98-5,20)$ & $2,99(1,06-8,39)$ \\
Common Mental Disorders & $2,81(1,28-6,15)$ & $5,73(2,29-14,34)$ \\
\hline
\end{tabular}

When retaking the findings related to the factors associated three points are relevant: sex, school repetition and Common Mental Disorders.Our finding of sex indicates that our young boys are 3.75 times more likely to be abusive than our girls, which is widely corroborated by the literature. However, it is important to point out that in a second analysis when separating by sex we realize that when we analyze only the women, the association remains in the same direction, but to a lesser extent than the boys. So we can say that although we should focus our attention on the young men who have a more marked behavior by the action we should not underestimate the potential of these women for abuse. School repetition translating lower school performance may not be the best parameter, especially as we have the limitation of a high percentage of repetition in our schools. The high number of repeaters can be explained in consonance with the average age in association with the predominance of public schools. One of the limitations of the study was the high refusal of the private schools that concentrate the best-performing students here, translated for less reproach. However, this did not prevent us from verifying that there was an association between greater repetition and abusive use of games, thus aligning with the predominance of published studies on the subject. Mental Disorders are associated factors detected in important investigations and targets of the DSM-V of the American Psychiatric Association when it has been spoken of in addiction and abuse of games. For logistic reasons, we decided to make the proposal for the detection of CMD in our study. We use the already validated and tested SRQ-20 $0^{15}$ in auto-application mode and, we find the strong association with the abusive use of games. Should we consider that there could be a possible limitation that would be the presence of a bias of reverse causality, that is, the presence of CMD would be the cause or consequence of abusive use? We do not pretend to answer this question since it would not be possible with our study design, but we have, as preponderant, that a PR of more than 5.78 should be strongly considered and more deeply studied. The burning question is whether some manifestations that constitute Common Mental Disorders will not be part of a set of signs and symptoms that, when associated with signs and symptoms of abusive use of electronic games, will not come, in the not too distant future, diagnostic criteria for something that would characterize Internet Gambling Disorders.

\section{Conclusion}

Our investigation contributes to the detection, in our environment, of the prevalence of abuse of electronic games. In addition to being able to indicate important factors associated. Early detection of such abusive behavior may provide support for both preventive and curative interventions in mental health. Reducing these abusive behaviors that are causes, consequences, or even a specific future psychiatric picture will bring more health and these young people as well as their current and future families. Thus, more and detailed research should be encouraged on the topic of electronic game abuse and awareness actions of educators, health professionals and family on such behaviors should be stimulated and established.

\section{Acknowledgements}

None.

\section{Conflict of interest}

The author declares that there is no conflicft of interest.

\section{References}

1. Przybylski A K, Weinstein N, Murayama K. Internet gaming disorder: investigating the clinical relevance of a new phenomenon. $\mathrm{Am} \mathrm{J}$ Psychiatry. 2016;174(3):230-236.

2. Ustinavičienė R, Škėmienė L, Lukšienė D, et al. Problematic computer game use as expression of Internet addiction and its association with 
self-rated health in the Lithuanian adolescent population. Medicina. 2016;52(3):199-204

3. American Psychiatric Association. Manual diagnóstico e estatístico de transtornos mentais: texto revisado (DSM-IV-TR). Artmed. 2002;1-199.

4. Lemos IL, Santana SDM. Electronic games dependency: the possibility of a new psychiatric diagnosis. Rev psiquiatr clín. 2012;39(1):28-33.

5. Abreu CND, Karam RG, Góes DS. Internet and videogame addiction: a review. Rev. Bras. Psiquiatr. 2008;30(2):156-167.

6. Maras D, Flament MF, Murray M, et al. Screen time is associated with depression and anxiety in Canadian youth. Preventive medicine. 2015;73:133-138.

7. Arab E, Sommer K, Herkovic V, et al. Evaluation of the use of video games in schoolchildren in the metropolitan region. Rev Soc Psiquiatr Neurol Infanc Adolesc. 2007;18(2):7-11.

8. Castrén S, Grainger M, Lahti T, et al. At-risk and problem gambling among adolescents: a convenience sample of first-year junior high school students in Finland. Substance abuse treatment, prevention, and policy. 2015;10(1):9.

9. Kiatrungrit K, Hongsanguansri S. Cross-sectional study of use of electronic media by secondary school students in Bangkok, Thailand. Shanghai Arch Psychiatry. 2014;26(4):216.

10. Haghbin M, Shaterian F, Hosseinzadeh D, et al. A brief report on the relationship between self-control, video game addiction and academic achievement in normal and ADHD students. J Behav Addict. 2013;2(4):239-243.

11. Schmitt ZL, Livingston MG. Video game addiction and college performance among males: results from a 1 year longitudinal study. Cyberpsychology, Behavior, and Social Networking. 2015;18(1):25-29.
12. Hofferth S L, Moon UJ. Electronic play, study, communication, and adolescent achievement, 2003-2008. JRes Adolesc. 2015;22(2):215-224.

13. Lemos IL, Conti MA, Sougey EB. Semantic equivalence and internal consistency evaluation of Game Addiction Scale (GAS): Portuguese version. Brazilian Journal of Psychiatry. 2015;64(1):8-16.

14. Lemmens JS, Valkenburg PM, Peter J. Development and validation of a game addiction scale for adolescents. Media Psychology. 2009; 12(1):77-95.

15. Gonçalves DM, Stein AT, Kapczinski FP. Performance of the SelfReporting Questionnaire as a psychiatric screening questionnaire: a comparativestudy with Structured Clinical Interview for DSM-IV-TR. Cadernos de saúde pública. 2008;24(2):380-390.

16. Przybylski AK. Electronic gaming and psychosocial adjustment. Pediatrics. 2014;134(3):e716-e722.

17. PrzybylskiAK, Deci EL, Rigby CS, et al. Competence-impeding electronic games and players' aggressive feelings, thoughts, and behaviors. Journal of personality and social psychology. 2014;106(3):441-457.

18. Przybylski AK, Rigby CS, Ryan RM. A motivational model of video game engagement. Review of general psychology. 2010;14(2):154-166.

19. Strittmatter E, Kaess M, Parzer P, et al. Pathological Internet use among adolescents: Comparing gamers and non-gamers. Psychiatry Res. 2015;228(1):128-135.

20. Brezing C, Derevensky J L, Potenza MN. Non-substance-addictive behaviors in youth: Pathological gambling and problematic internet use. Child Adolesc Psychiatr Clin N Am. 2010;19(3):625-641. 